\title{
LAS REDES DE CONOCIMIENTO LOCALES EN EL DESARROLLO TERRITORIAL DE LA CAMPIÑA SEGOVIANA ${ }^{1}$
}

\author{
Miguel Ángel Gandarillas Solinís \\ Raquel Yagüe Muñoz \\ IE Universidad \\ Segovia
}

\section{RESUMEN}

La situación actual de una comarca rural y sus necesidades y recursos es aquí estudiada desde un enfoque integral del territorio, incluyendo ámbitos demográficos, económicos, y psicosociales. Se realizaron análisis de datos estadísticos, de entrevistas etnológicas, y de visitas de campo en lugares representativos, integrando la información cuantitativa y cualitativa. Los resultados apoyan la hipótesis general de que el eje principal que explica la situación es el nivel de integración o fracturación social con el territorio, tanto en el ámbito socioeconómica como en el plano psicosocial, y en particular en relación a los conocimientos locales y la vinculación afectiva con el medio rural. Se propone una serie de estrategias de desarrollo comarcal, centradas en la gestión de las redes de conocimiento local en cadenas de valor desde la creatividad colectiva, la innovación, interemprendedora y el papel de la empresa como motor de generación y desarrollo de conocimiento local y capital social. Buscamos así generar relación activa, dinámica, interadaptada, flexible, diferenciada y personalizada, entre territorio origen del producto y demanda final con el apoyo de las nuevas tecnologías de la comunicación. Para poder comprender las dinámicas demográficas territoriales se incluye en el estudio un nuevo índice de concentración poblacional.

Palabras clave: Conocimiento local, cadenas de valor, desarrollo territorial, desarrollo sostenible, desarrollo rural, capital social.

1 Los resultados aquí presentados son resultado del proyecto de investigación «Recursos Sociales, Económicos, y Etnológicos de la Campiña Segoviana» dirigido por el primer autor del presente artículo, que se integra en el estudio general sobre Recursos de la Campiña Segoviana de la IE Universidad a solicitud de AIDESCOM (entidad que gestiona la agencia de desarrollo local de la Campiña Segoviana). Agradecemos la colaboración de Itziar Jiménez, Patricia Peinador, y la profesora Carmen Merino por dedicar buena parte de un verano a la recopilación de datos de los municipios de la Campiña. 


\begin{abstract}
An analysis of present development needs and resources of a rural county, based on an integral approach including demographic, economic, and psychosocial domains, is presented here. We stated as a general hypothesis that both needs and resources are mainly explained by the degree socio-economical and psychosocial integration vs. fragmentation with land. Socio-demographic and economic statistical data analysis, ethnological interviews, and field research of selected places were carried out. After an analysis integrating results on social features, perceived needs, and identified resources, main hypothesis was supported, being local knowledge and affective binding to the rural context particularly affected by a increasing fissure between society and land. Community development based on local knowledge management within value network and chain systems is proposed as strategy to enhance social capital and fabric, through knowledge exchange, creativity, and interpreneurial innovation, and the role of companies as enginer of generation and development of local knowledge, aiming at a dynamic, flexible, differentiated, active and personalized relationship between the land origin of the product and the final demand, with the aid of new communication technologies In order to understand the land demographic dynamics of this study, a new population concentration index is introduced.
\end{abstract}

Key words: Local Knowledge, Value Chain, Land Development, Sustainable Development, Rural Development, Social Capital.

\title{
1. Introducción
}

El territorio, entendido como un espacio definido por una serie de lugares con una relación significativa y diferenciadora, se ha mermado aceleradamente como recurso de desarrollo local en las últimas décadas no solo en España, sino que podemos considerarlo una tendencia internacional. La continua y acelerada concentración social y económica en núcleos urbanos a costa del territorio rural, la centralización de los flujos productivos en ejes territoriales, la especialización y pérdida de diversidad económica de comarcas y regiones, han estado implícitos en los modelos económicos de progreso y desarrollo social predominante. Pero al mismo tiempo, han supuesto un negativo impacto social, cultural, ambiental, y a largo plazo económico (Escobar, 2000). La fractura, desconexión, y desigual distribución de las actividades, redes, y tejidos socioeconómicos adaptados al territorio y a su diversidad suponen un continuo empobrecimiento del número de actividades y grado de conocimientos sobre el lugar y sobre sus potencialidades (Hester, 2006). Todo ello ha conllevado una desvalorización del territorio, del lugar, y de todo lo ligado a él (Borja y Castells, 1997), y una consiguiente degradación ambiental y cultural y de los productos que necesariamente surgen del territorio.

Todo ello se observa con gran claridad en el medio rural, emblema de lo que hoy entendemos por territorio: cambios de modelos productivos que caracterizan lo rural hacia modelos más especializados, industrializados, y urbanos, el continuo y aparentemente imparable éxodo juvenil, la relación directa entre tamaño de una población y su crecimiento, el aumento de la inequidad territorial, social y económica (Esteva, 2000; Solo, 2000), han ido «desterritorializando» su población (Entrena, 1999), desequilibrando redes territoriales socioeconómicas, fragmentando cadenas productivas ligadas a este, disminuyendo la diversidad económica, su cohesión y capital social, y especialmente, empobreciendo y marginando la riqueza de conocimientos locales ligada a esa diversidad económica y ecológica (Douw van der Ploeg, 2000; Escobar, 2000, Millar, Haverkort, van Hooft, and Hiemstra, 2002; RENPA, 2002). Esto se relaciona con una gran desvalorización de lo rural a favor de lo urbano, que se asocia poderosamente con el «desarrollo», el «progreso», el «éxito», el «poder». Los problemas 
psicosociales del campo español se suelen mencionar como un efecto de la problemáticas generales, aunque cada vez se estudia más a las primeras como origen impulsor de las segundas (Lesta, 2001; Medina, 1996; Montero, 1998; Montero, 2004; García y García, 2004).

Pero ¿es así de grave la situación? ¿hay soluciones? En las últimas décadas se han ido multiplicando proyectos pilotos y propuestas para dar soluciones a los problemas del mundo rural (Champetier, 2002; Márquez, 2002), aunque en su mayoría con resultados desiguales, excesivamente sectoriales (y aislados), hasta la fecha poco concluyentes (Márquez y Jurado, 2004; Maya, 2004; Somoza, 2004), y ofrecen poca luz que nos permita una visión esperanzador del futuro rural. Los cambios espontáneos que están sucediendo en el campo español, como la creciente urbanización o la introducción de la inmigración internacional, son propuestos a veces como solución a los problemas relacionados con el despoblamiento rural. Pero ¿hasta qué punto estos fenómenos darán solución a estos problemas?

El presente estudio aborda estas preguntas centrándose en un caso que muestra características comunes de la geografía rural española, que es la comarca histórica de La Campiña Segoviana, en el centro de la Península Ibérica. Analizamos aquí los fenómenos que están sucediendo en la actualidad, y señalamos propuestas identificadas como posibles respuestas a los dilemas de la crisis del mundo rural en particular y del territorio en general. Primero se describen y analizan las características y procesos demográficos territoriales y las principales necesidades y recursos de la población desde un enfoque integral, multisectorial, e interdisciplinar. Después se concluye con una serie de líneas estratégicas de desarrollo comarcal fruto de este estudio.

Partimos de la hipótesis general de que el balance de las actuales dinámicas territoriales es de fragmentación y desequilibrio demográfico, económico, y psicosocial, y está relacionado con modelos y fenómenos de desarrollo desligados del territorio. Éste es el factor principal que explica las principales necesidades y problemas de la comarca y situación de sus recursos. También, planteamos la hipótesis de que las actividades y conocimientos locales, tradicionales, y populares han sido y pueden ser recursos para el desarrollo local sostenible que aborden estos problemas por sus valores territoriales.

\section{Metodología}

El procedimiento de investigación ha tenido varias fases, que incluyen diferentes participantes, y técnicas de recogida y procesamiento de la información:

1. Estudio previo y diseño de proyecto. El diseño inicial del proyecto partió de un análisis de fuentes secundarias y bibliográficas, especialmente sobre la comarca de la Campiña Segoviana, y de un trabajo de campo inicial que incluyó varias entrevistas con agentes sociales.

2. Entrevistas etnológicas. Se entrevistaron al menos a dos personas por cada municipio:un representante (alcalde o secretario) y un informante-clave (lugareño con amplio conocimiento de la zona). En total fueron 102 entrevistados. En general, la identificación del informante-clave era realizada por el representante. La gran mayoría de las entrevistas etnológicas fueron realizadas telefónicamente, con un guión y cuestionario con preguntas sobre necesidades percibidas, calidad de vida, y recursos seleccionadas en base a una serie de hipótesis de trabajo surgidas del estudio bibliográfico y de un trabajo de campo inicial en la Campiña.

3. Investigación de campo, de profundización sobre necesidades y recursos, con documentación fotográfica y 25 entrevistas en profundidad de aquellos agentes o informantes representativos. 
4. Selección de recursos. De los recursos identificados en el estudio bibliográfico y las entrevistas del estudio, se seleccionó una serie de ellos con mayor valor, en desde los siguientes criterios en base a modelos teóricos y experiencias sobre patrimonio cultural y natural y desarrollo sostenible (por ejemplo, Díaz, 1984, 1998; Hammersley y Atkinson, 1994; Mauss, 1990; Troitiño, 2000): Estado de preservación, vulnerabilidad, significatividad, representatividad, singularidad, valor social, valor económico, valor cultural, y valor ambiental.

5. Recogida y procesamiento de datos. La información del estudio bibliográfico fue volcada a un banco de datos de fichas de elementos de patrimonio / recursos. La información de las entrevistas fue organizada en otro banco de datos. Los elementos surgidos de las entrevistas fueron también incorporados al banco de datos.

6. Análisis de los datos. Los datos cuantitativos fueron analizados estadísticamente (utilizando el programa informático SPSS). Los datos cualitativos fueron de dos tipos, los incluidos en las preguntas abiertas del cuestionario y los obtenidos de las entrevistas de campo. La información cualitativa se combinó con la cuantitativa en amplitud y profundidad. Al mismo tiempo, los dos tipos de datos fueron utilizados como criterios de validez cruzada. Se procedió a una segunda sección de recursos en base a los siguientes criterios: (1) Valorados por la población y/o sus agentes sociales; (2) Característicos de la Campiña; (3) Con alto valor o potencial económico, social, cultural, o ambiental; (4) Con valor estratégico; y (5) Con valor de cohesión social y como capital social.

7. Resultados e interpretación. Los resultados de los diferentes campos fueron integrados, dando lugar a una serie de líneas prospectivas y proyectivas sobre los potenciales de los recursos sociales de la Campiña Segoviana para poder satisfacer las necesidades identificadas.

\section{Resultados y discusión}

La comarca de la Campiña Segoviana se trata de un territorio histórico de $1654 \mathrm{Km}^{2}$ en el centro-oeste de la provincia de Segovia que ha mantenido territorialmente su estructura

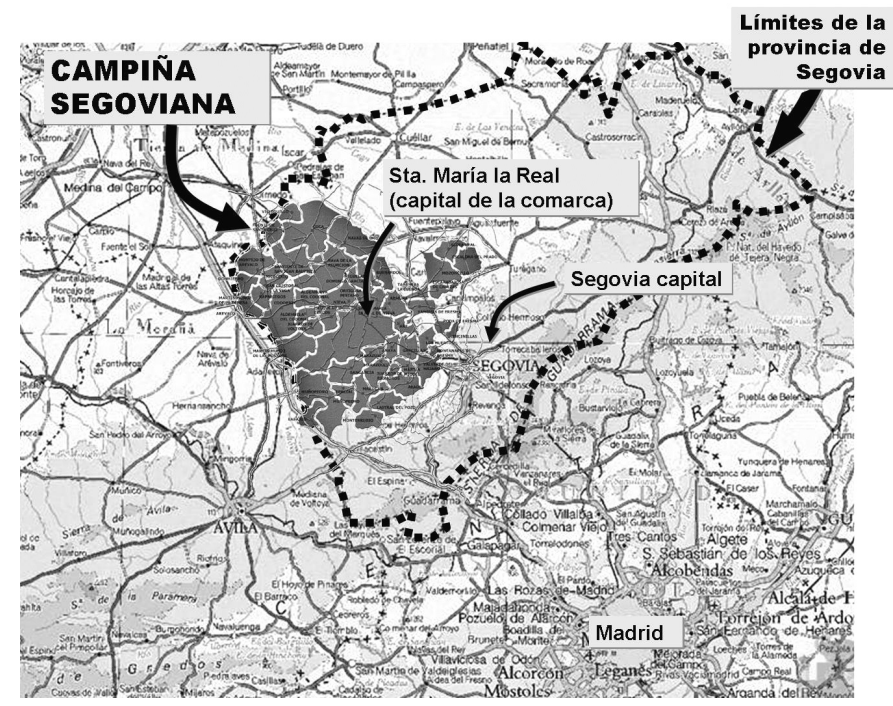


demográfica junto a sus conocimientos, costumbres, y actividades a través de cientos de años. En cambio, en las últimas décadas el territorio lleva experimentando unos cambios demográficos que afectan profundamente a la estructura social y económica a nivel territorial.

\subsection{Demografía y territorio}

\subsubsection{Pirámide poblacional}

El Censo de 2001 (INE) muestra un total de habitantes de 19.987 habitantes, de los cuales 10247 eran hombres y 9740 mujeres, que indica una cantidad mayor de mujeres emigradas, común en la emigración rural de todas España. De hecho, el análisis de la pirámide poblacional muestra claramente de dónde vienen las diferencias (ver Figura 1). Mientras que se observan más mujeres en edades altas, por su mayor esperanza de vida, en las edades medias (30-45 años), donde se observa el otro pico demográfico, el número de mujeres es menor, resultante de una mayor migración femenina.

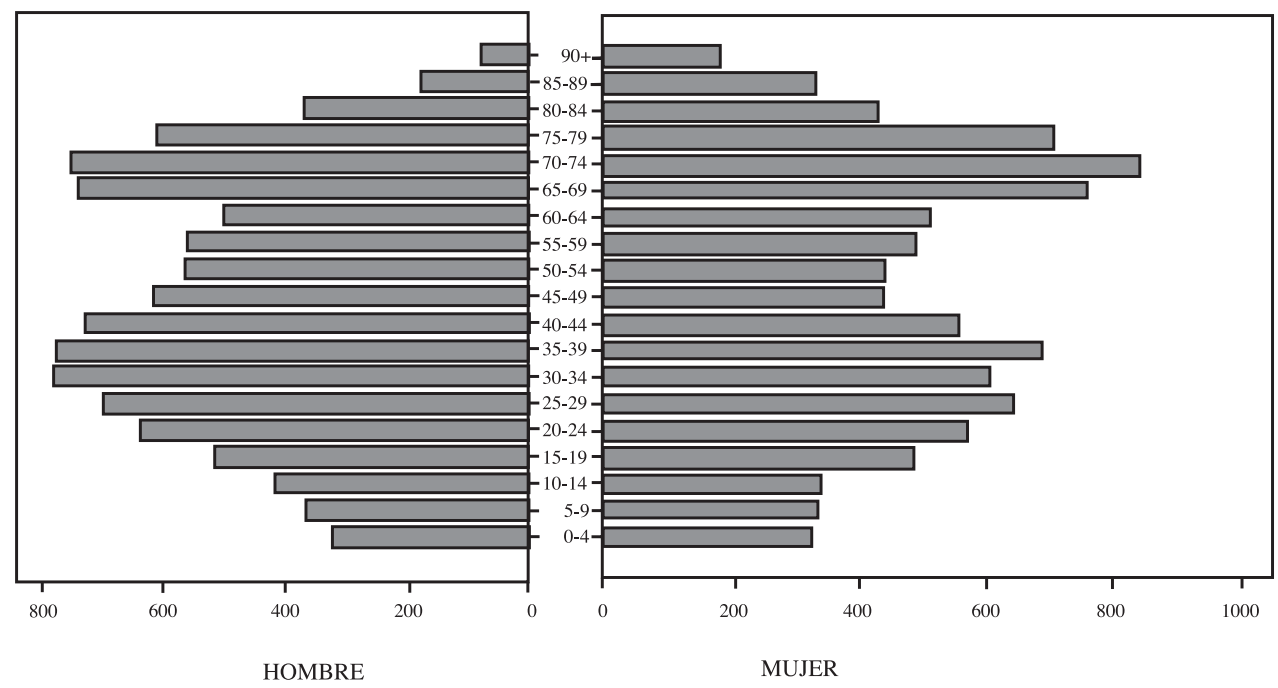

Figura 1. Pirámide poblacional de la Campiña Segoviana. Censo 2001 (Fuente: INE).

Se observa una serie de discontinuidades que muestra los vaivenes y crisis de la historia reciente del mundo rural español. La primera gran caída demográfica (edades entre 45 a 60), refleja la primera y más fuerte emigración rural de los años 60 y 70, después un repunte entre los 30 a 45, del «baby-boom» de los nacidos entre los 60 y 70, acabando finalmente con la pirámide truncada en las primeras edades, fruto de la enorme caída demográfica de toda España. Resaltar la enorme proporción de mayores. La pirámide nos revela un panorama fracturado y desequilibrado generacionalmente.

¿Se está viendo reflejado este desequilibrio a nivel territorial? En la Figura 2 se puede apreciar las edades medias por cada municipio (Censo 2001). En el 2000 los municipios más jóvenes se concentraban alrededor de los principales núcleos urbanos limítrofes 
con la comarca (Arévalo, Cuellar, y Segovia). Los municipios más envejecidos son los centrales en la organización y tejido social comarcal, por lo que los desequilibrios en edades pudieran predecir futuros desequilibrios territoriales de distribución (concentración/dispersión) demográfica. El fenómeno precisa un análisis en profundidad si además a eso añadimos el efecto de los recientes flujos inmigratorios, que pueden aumentar estos desequilibrios generacionales, al incidir sobre todo en las edades medias, justo las del pico de 30 a 45 .

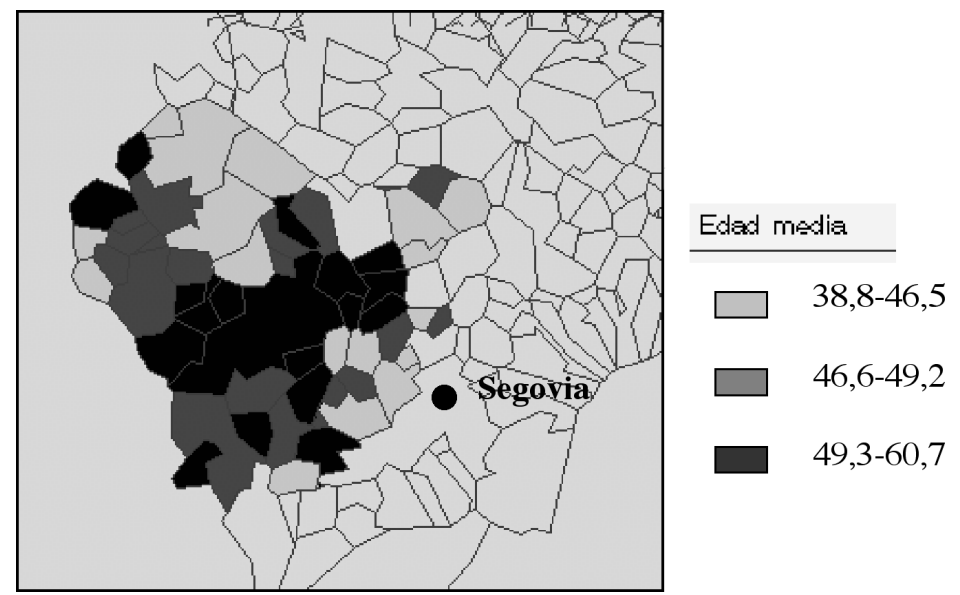

Figura 2. Mapa de edades medias de los municipios de la Campiña (Fuente: INE).

\subsubsection{Densidad de población}

La densidad era en la comarca de 12.4 hab. $/ \mathrm{km}^{2}$ en 2000 y de $12.8 \mathrm{hab} . / \mathrm{km}^{2}$ en 2007 (en base a datos del padrón), un cambio muy pequeño, pero que no refleja los cambios en la distribución demográfica interna entre los municipios de la comarca. Mirando las densidades a nivel municipal (Tabla 1), podemos observar sobre todo un gran aumento en la variabilidad de las densidades entre 2000 y 2007 (desviaciones típicas y máximos mucho mayores, mínimos menores), lo que nos está sugiriendo una tendencia hacia la concentración demográfica en cierto número de municipios, debido probablemente a los movimientos emigratorios e inmigratorios. Esta información es en cambio insuficiente, ya que ante dos municipios con mismas densidades no podemos inferir el mismo grado de concentración de la población comarcal.

Precisamos aquí profundizar sobre estos cambios de la estructura territorial y de distribución geográfica poblacional, ya que nos pueden ofrecer una información fundamental a la hora de entender los cambios en los modelos de uso y aprovechamiento de los recursos del territorio, y en la propia relación con él. Para ello necesitamos indicadores directos de los pesos demográfico relativos de los municipios sobre todo el territorio bajo estudio para tener una medida precisa del grado de concentración territorial de la población comarcal en los diferentes municipios, que veremos a continuación.

\section{Tabla 1}


DENSIDADES DEMOGRÁFICAS DE MUNICIPIOS DE LA CAMPIÑA SEGOVIANA (BASADO EN PADRÓN MUNICIPAL; FUENTE: INE)

\begin{tabular}{|l|c|c|c|c|c|}
\hline & N & Mínimo & Máximo & Media & $\begin{array}{c}\text { Desv. } \\
\text { típ. }\end{array}$ \\
\hline Densidad de población 2000 & 50 & 2,27 & 31,58 & 11,87 & 7,20 \\
\hline Densidad de población 2007 & 50 & 2,17 & 111,83 & 13,74 & 16,08 \\
\hline
\end{tabular}

\subsubsection{Movimientos demográficos y cambios en la distribución geográfica}

El padrón municipal de 2000 muestra una tímida presencia de población extranjera (129 personas, un $0.6 \%$ de la población). En cambio, el padrón de 2007 nos indica un importante crecimiento en solo 7 años, 1590 extranjeros (7.6 \% población). Si en estos 7 años la población de la Campiña ha pasado de 20121 a 20837, un incremento del 3.6\%, es la inmigración extranjera la que ha contribuido mayoritariamente a este aumento (salvo casos excepcionales, sobre todo correspondientes al extrarradio de Segovia, cuyos desarrollo urbanísticos han recibido nuevos residentes de la ciudad). La población de origen español tuvo un balance negativo y disminuyó en un $3.7 \%$.

El gráfico 1 nos muestra la distribución porcentual de la población de la Campiña por municipios y cómo se ha distribuido el cambio de población nacional y extranjera entre 2000 y 2007. Se puede observar que en 2000 las proporciones demográficas por municipios guardaban más homogeneidad distributiva. También, por un lado los cambios de residentes nacionales son dispares y no parecen guardar una relación lineal con las cantidades relativas de población de cada municipio. Esto se podría explicar por dos características territoriales: (1) Aquellos municipios con números negativos coinciden con municipios muy rurales con actividades agropecuarias tradicionales y baja densidad de población; y (2) Aquellos municipios con gran crecimiento relativo de población española coinciden con municipios con grandes desarrollo urbanísticos que están absorbiendo población urbana, en particular del extrarradio de Segovia. Por otro lado, la población inmigrante extranjera sí que muestra una relación más lineal con las proporciones distributivas de la población comarcal, tendiendo a instalarse en los municipios con más habitantes. Todos estos movimientos vuelven a mostrar un rápido aumento subyacente de la concentración demográfica. Este fenómeno es de gran importancia, ya que de seguir la dinámica supone romper con una distribución más homogénea y una estructura territorial tradicional más equilibrada, lo que podría implicar cambios profundos que afectaría a la planificación y ordenación territorial de las diferentes actividades sociales y económicas. Pero más importante es que estos movimientos demográficos nos pueden estar indicando un cambio hacia modelos productivos más desligados del territorio, de sus recursos y de sus valores.

Debido a su importancia, hemos querido estudiar más en profundidad esta dinámica de concentración demográfica ya que los indicadores demográficos más sencillos (número de habitantes, porcentajes y densidad) no nos dan una idea precisa del grado de concentración o dispersión poblacional. Así, un municipio puede ser muy denso, pero si su superficie es muy pequeña, no supone un núcleo de alta concentración comarcal. Así mismo, un municipio con densidad media pero gran superficie puede estar escondiendo 


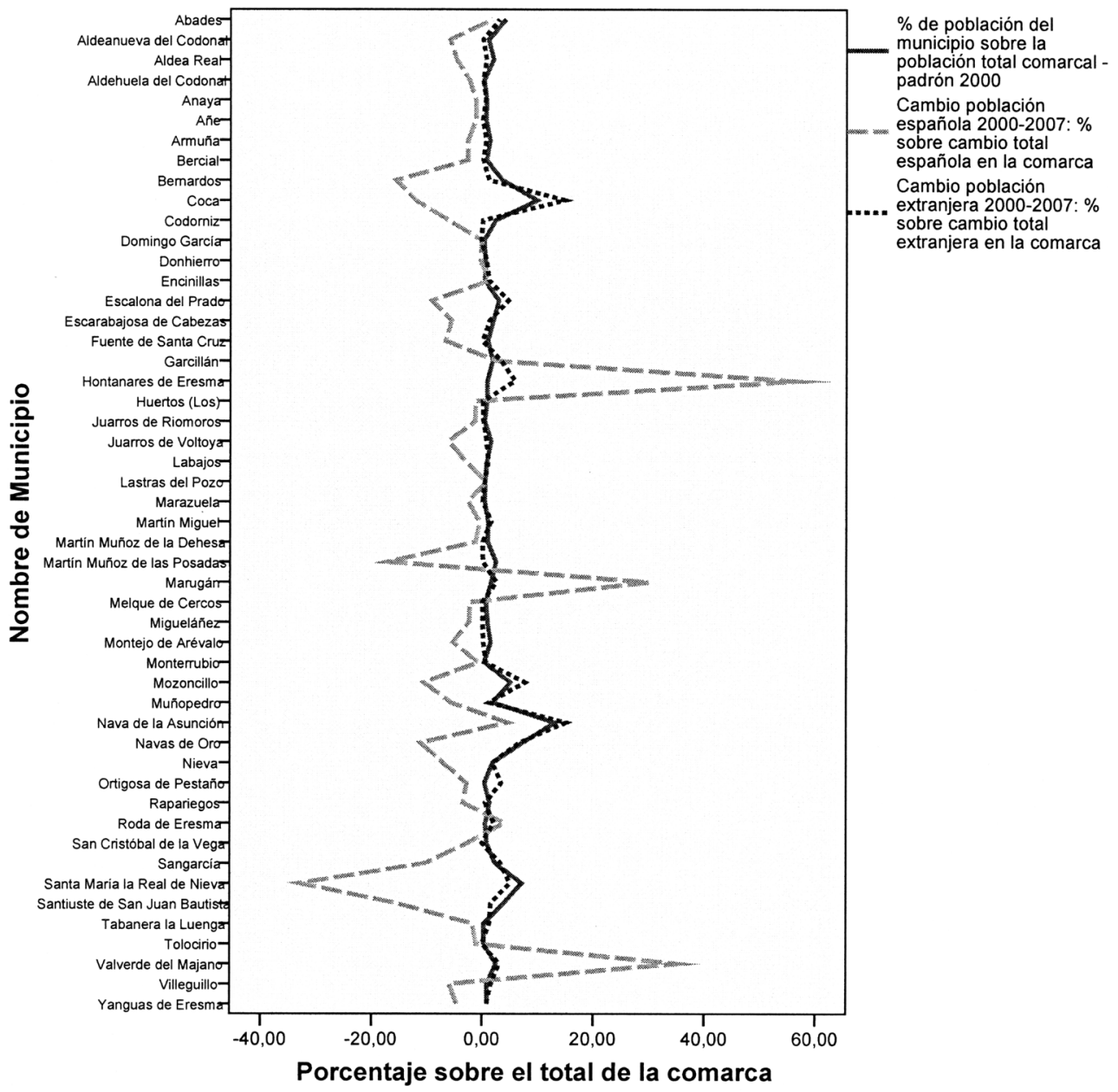

GRÁfICo 1. Distribución porcentual por municipios de la población de la Campiña Segoviana (Padrón 2000) y distribución de los cambios de 2000 al 2007 (datos del Padrón) de la población de origen español y de origen extranjero (elaborado del INE).

altas proporciones. Habida cuenta del sesgo que supone las diferencias en superficie de los municipios de la comarca, y para poder precisar mejor este fenómeno, creamos un índice de concentración territorial de la población. Para ello, para cada municipio multiplicamos su densidad de población por su porcentaje de población dentro de la comarca obteniendo un índice preciso del grado de concentración poblacional comarcal de cada municipio. En la Tabla 2 tenemos los resultados de comparar 2001 y 2007. Todos los indicadores de concentración muestran un importante aumento medio de la concentración entre 2000 y 2007 a la par que un aumento en las diferencias entre municipios con más concentración y municipios más dispersos. 
Tabla 2

CONCENTRACIÓN POBLACIONAL (PORCENTAJE DE POBLACIÓN DE LA CAMPIÑA X DENSIDAD DE POBLACIÓN) POR MUNICIPIO (ELABORADO DEL PADRÓN MUNICIPAL, FUENTE INE)

\begin{tabular}{|l|c|c|c|c|c|}
\hline Índice de Concentración & $\mathrm{N}$ & Mínimo & Máximo & Media & Desv. típ. \\
\hline 2000 & 50 &, 66 & 411,35 & 35,38 & 68,82 \\
\hline 2007 & 50 &, 48 & 477,93 & 43,88 & 90,18 \\
\hline
\end{tabular}

La progresiva concentración demográfica que experimenta la comarca en varias áreas parece relacionarse con su dedicación a ámbitos económicos como puede ser la construcción, los servicios, y nuevos regadíos. En cambio, la progresiva dispersión comarcal (junto al continuo éxodo autóctono) se da en municipios dedicados a actividades tradicionales agropecuarias.

\subsection{Economía}

La Campiña Segoviana es una comarca rural que ha vivido de la economía primaria, en particular de la agricultura y ganadería, con cambios lentos y progresivos en las últimas décadas. Por regla general, ha mantenido históricamente cierta autosuficiencia y estabilidad a través de las generaciones, y ha obtenido excedentes con los que ha abastecido y sigue abasteciendo de alimentos a su entorno geográfico. Los índices socioeconómicos de la Campiña no divergen especialmente del resto de la Segovia rural ni en tipo de economía ni en nivel económico. En cuanto al número de trabajadores por ramas económicas, en la Campiña Segoviana, a fecha de 2001 (Censo, INE), de las personas ocupadas, un 26\% trabajaba en establecimientos agropecuarios, un $16 \%$ en la industria, un $12 \%$ en la construcción, y un $45 \%$ en los servicios, proporcionalidad que se mantiene por regla general a través de los municipios, y al número de habitantes de cada municipio. En los últimos años no ha habido grandes cambios en estas proporciones, exceptuando la de la rama construcción, que ha aumentado en ciertos municipios, coincidentes con aquellos que muestran altos aumentos de población.

\subsection{Necesidades sociales y económicas percibidas}

Las siguientes análisis nos servirán para indagar desde el nivel individual y psicosocial hasta qué punto se sostienen los planteamientos expuestos en el análisis demográfico previo y para profundizar sobre la relación entre necesidades y recursos del territorio bajo estudio. Los siguientes resultados parten de la información recogida en las entrevistas etnológicas, y no puede entenderse como un estudio estadísticamente representativo, sino como ilustrativa de las opiniones de los agentes sociales formales e informantes clave de todos los municipios de la Campiña. Aunque se incluyeron todas las edades, abundaban los mayores (edad media de la muestra, 49 años, desviación típica 14.4), y un mayor número de hombres (un $52 \%$ ) que de mujeres. La mayoría (77) de los entrevistados crecieron en el mismo municipio donde residen actualmente, siendo minorías los que crecieron en otro municipios de la comarca (9), de la misma provincia (4), misma región (6) y otras regiones (6). 


\subsubsection{Resultados cuantitativos}

Las preguntas realizadas trataron por un lado aspectos propios de la persona, de su satisfacción y calidad de vida percibida, y por otro lado las percepciones sobre la gente de su lugar. Se muestra aquí una síntesis de los resultados más significativos. En general las personas se manifiestan satisfechas con el lugar (media 4,4 sobre 5), sin que haya una gran diferencia de género. Esta satisfacción no parece tener mucho que ver con la procedencia de las personas (entre 3,8 sobre 5 de los procedentes en la misma provincia y 4,5 los del municipio). En cambio, se percibe una diferencia en relación con la dedicación de la persona, siendo los más satisfechos los empresarios de comercio y sanitarios (5 sobre 5), y los agricultores y ganaderos los menos satisfechos con el lugar (3 sobre 5). Sobre el apoyo social percibido, se observan diferencias, aunque por lo general se percibe como alto (media 3,8 sobre 5). Cabe resaltar el más bajo apoyo percibido por agricultores y ganaderos, alguaciles, y sanitarios (3 sobre 5). En el extremo positivo cabe incluir a los empresarios ( 5 sobre 5). En cuanto al nivel de participación personal en la comunidad, se percibe generalmente alto (media 4,2 sobre 5), aunque hay que tener en cuenta que más de la mitad de la muestra son representantes municipales o relacionados con el ayuntamiento. La gente por lo general se siente del lugar (media 4,5 sobre 5), aunque naturalmente se vean diferencias dependiendo del lugar de procedencia o donde creció la persona, siendo las del mismo municipio las que más se identifican con el lugar (5 sobre 5).

Sobre indicadores de calidad de vida, se expresa una baja frecuencia en sentimientos negativos (media 1,7 de 5) y alta en sentimientos positivos (media 4.3). El nivel general de calidad de vida percibida es alto (4.1 sobre 5), y no aparecen grandes diferencias de género o edad. Desglosado en dedicaciones, las diferencias son mínimas (situándose entre 4 y 5), lo que choca con las diferencias sobre la satisfacción con el lugar, sugiriendo que el concepto de calidad de vida no se asocia necesariamente al lugar. En relación a las percepciones sobre la gente del lugar, aparece por regla general una mayor variabilidad. Llama la atención el nivel medio de conocimiento que se percibe que tienen sus vecinos sobre el lugar y sobre sus valores culturales y naturales (3.7 sobre 5). Tampoco perciben que la gente tenga una alta opinión sobre el futuro de su lugar (media 2.8) y sobre la existencia los proyectos futuros (media 2.6), aunque la variabilidad en amplia (desviación típica 1.2 y 1.1 respectivamente). En cambio, se perciben bajos deseos de emigrar (1.9 de media sobre 5). Se observan diferencias en tipos de dedicación, con respuestas más positivas de los representantes y empleados municipales (alrededor de 4 sobre 5), y más negativas entre empresarios no comerciales, agricultores, amas de casa, y sanitarios (entre 1 y 2 sobre 5).

Para ahondar en la relación entre variables, se procedió a realizar un análisis factorial entre ellas (Tabla 3), con una solución de (con un 52\% de varianza total explicada) 3 factores conceptualmente muy significativa: la percepción sobre el entorno social (20\% de varianza explicada), la relación de uno mismo con su entorno (16\% de varianza), y la percepción de calidad de vida propia (16\% de varianza total explicada). Aparecen pues como tres dimensiones independientes, sugiriendo que, para la muestra aquí incluida, la percepción de calidad de vida no dependiera tanto de la gente del lugar y ni siquiera de las relaciones con la gente del lugar. Pareciera que la percepción de calidad de vida esta más asociada a la ausencia de factores negativos internos que a la relación con el entorno. Esto choca con las concepciones de calidad de vida en los ámbitos urbanos, donde el entorno aparece como fundamental (Borja y Castells, 1997; Hester, 2006). Sólo una variable está a caballo entre la calidad de vida y la percepción sobre el entorno 
social que es la satisfacción sobre el lugar. Una explicación de estos resultados es que la calidad de vida y el bienestar percibido se están asociando más al entorno personal, es decir, la casa y los allegados, que entienden como «su lugar», que al comunitario. De esta hipótesis se inferiría una separación psicológica entre relación con el medio social y percepción de calidad de vida en este medio rural.

Tabla 3

ANÁLISIS FACTORIAL VARIABLES DE PERCEPCIÓN SOBRE UNO MISMO Y SU ENTORNO

Matriz de componentes rotados(a)

\begin{tabular}{|l|r|r|r|}
\hline & \multicolumn{3}{|c|}{ Componente } \\
\hline & \multicolumn{1}{|c|}{1} & \multicolumn{1}{|c|}{2} & \multicolumn{1}{c|}{3} \\
\hline Gente piensa que hay futuro en el lugar &, 91 & & \\
\hline Gente piensa que hay proyectos de futuro &, 86 & & \\
\hline Gente desea irse a otro lugar &,- 48 & & \\
\hline Identificación propia con el lugar & &, 75 & \\
\hline Participación propia en la comunidad & &, 64 & \\
\hline Apoyo social percibido hacia uno & &, 58 & \\
\hline Gente conoce el patrimonio cultural y natural & &, 53 & \\
\hline Frecuencia de sentimientos negativos & & &,- 70 \\
\hline Percepción de propia calida de vida & & &, 62 \\
\hline Frecuencia de sentimientos positivos & & &, 57 \\
\hline Satisfacción propia con el lugar &, 43 & &, 49 \\
\hline
\end{tabular}

Método de extracción: Análisis de componentes principales.

Método de rotación: Normalización Varimax con Kaiser.

Pesos y variables con pesos debajo de .40 excluidas de la tabla.

Se realizaron análisis post-hoc de validez entre estos factores y la variable edad, obteniendo interesantes correlaciones (Pearson) significativas con los tres factores: satisfacción sobre el lugar, $0.21(\mathrm{p}<.05)$, participación en la comunidad, $0.26(\mathrm{p}<.05)$ y frecuencia de sentimientos positivos, $0.29(\mathrm{p}<.01)$.

\subsubsection{Resultados cualitativos}

Las necesidades y problemas más mencionados en preguntas se pueden agrupar en las siguientes categorías, en orden de más a menos: la despoblación (un $24.3 \%$ de los entrevistados), la falta de servicios generales (un 12\%), el trabajo (un 11.5\%), aguas y sus infraestructuras $(7.5 \%)$, vías de comunicación (7.2\%), infraestructuras generales $(5.5 \%)$, alternativas de cultura y ocio $(5.4 \%)$, vivienda $(5.2 \%)$, recursos económicos $(5.2 \%)$, servicios para mayores $(5 \%)$ y comercios $(5 \%)$. Que el principal problema señalado en 
las preguntas abiertas sea el despoblamiento podría chocar con las respuestas negativas sobre si la gente desea emigrar. Los entrevistados parecen expresar que la gente aunque emigre no quiere. Asocian la emigración a problemas como la falta de servicios sociales y sanitarios para los mayores, y la falta de servicios culturales, de ocio, y de empleo para los jóvenes. Como dice un ama de casa, hay que «fomentar que la gente se quede allí y que hubiese más animación». Aunque algunos grupos señalan que por falta de trabajo no es por lo que se van los jóvenes. Una ama de casa ansía «que hubiese más gente joven aunque por trabajo no es porque sí que hay trabajo». Un alcalde se expresa en similares términos cuando habla del problema de la despoblación, «por trabajo no es ya que hay en el municipio un polígono industrial muy grande, pero allí trabajan solo 2 vecinos del pueblo». De hecho, una parte de los entrevistados apuntan a «la mentalidad» como el problema principal, por lo que creen que debe de cambiar, «y que la gente se quisiera quedar en el pueblo todo el año» indica un alcalde. Un trabajador de empresa privada encuentra que se hacen necesario «charlas de concienciación para que se valore el entorno rural, y para explotar los recursos que tenemos».

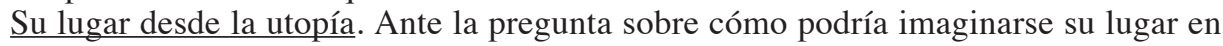
su ideal, las respuestas son sensiblemente diferentes a las relacionadas con las necesidades. Los entrevistados diferencian entre posibilidades reales e ideales, demostrando por lo general un fuerte realismo sobre la situación actual de sus municipios. Pero puestos a soñar, las respuestas sorprenden por su abrumadora similitud y coherencia. Los ideales se pueden agrupar en 7 categorías generales: demografía (46\% de respuestas), servicios $(12 \%)$, economía y trabajo (10\%), urbanismo (10\%), infraestructuras $(7.2 \%)$, medio ambiente $(4.3 \%)$, y comunidad (3\%). Las respuestas concretas más frecuentes son (en orden): Un crecimiento natural, sostenible, manteniendo la propia identidad (19.4\%); como está, acogedor y tranquilo (9.4\%); más gente joven (12.2\%); menos chalets, menos urbanizaciones masificadas, menos «urbano», más restauración de acuerdo con la identidad de la zona (6.5\%); más trabajo para que la gente se quede $(6.5 \%)$; más tiendas y comercios $(5 \%)$; más vida y dinamismos $(4.3 \%)$; más zonas verdes $(4.3 \%)$; más jóvenes y niños del pueblo $(4.3 \%)$.

La fotografía general de su lugar imaginado en un escenario ideal es bastante consistente. La mayoría de los entrevistados sueñan con un lugar donde los jóvenes no se vayan, manteniendo la identidad propia del lugar, la tranquilidad natural del lugar, y el dinamismo de los jóvenes. Por ejemplo, una ama de casa de Codorniz declara que soñaría que el municipio fuese «como era en el pasado, con una excelentes relaciones entre las personas, era muy familiar. Ahora hay muchas costumbres urbanas». Un alcalde desearía que «la gente que trabajara aquí se quedara a vivir también, que vivan las tradiciones, costumbres, que viva el pueblo».

Se observa un emergente rechazo a fórmulas que se extienden por la comarca, que relacionan con las nuevas urbanizaciones de segundas viviendas que rompen con las estructuras tradicionales de las poblaciones y con la entrada de nuevos habitantes no residentes asociados a ellas. Por ejemplo, un alcalde afirma que le gustaría que fuese «como era hace muchos años, un pueblo más pequeño y donde nos conocíamos todos. El pueblo ha crecido por tres en los últimos 3 años». A otro alcalde le preocupa el crecimiento sin control, y le gustaría que su municipio «no crezca con urbanizaciones tan exageradas como en otros pueblos está pasando».

Las entrevistas de campo supusieron una profundización y síntesis posterior sobre los temas más relevantes seleccionados en los estudios previos (bibliográficos y de las entrevistas telefónicas). Se entrevistó a personas de diferentes dedicaciones: agricultores, artesanos, ganaderos, amas de casa, alcaldes, comerciantes y personal de comercio, 
empresarios de industria, jubilados, estudiantes, y agentes de desarrollo local. De entre estos temas, reseñar los más esclarecedores y relevantes:

- El éxodo juvenil. Este tema es la constante cuando preguntamos sobre los principales problemas del municipio. Cuando se pregunta por las razones de este continuo goteo juvenil, la mayoría de los entrevistados tienden a dar distintas respuestas, siendo el tema laboral/económico el más general, y de forma más concreta, aparecen con más unanimidad: 1) Los bajos precios de los productos rurales; 2) Los grandes requisitos administrativos del trabajo de campo y el bajo apoyo de las administraciones para superar estas barreras; 3) La falta de atractivos para los jóvenes (pocos centros culturales, de ocio, o de consumo); y 4) El magnetismo de la ciudad unido a la desvalorización del medio rural. Este último factor es el principal para algunos. Un vecino señala que «los jóvenes van a Segovia porque hay más jóvenes y porque los gobiernos no promocionan el medio rural. No se lo enseña a los niños». En cambio, hay otros ejemplos de jóvenes que se empeñan en quedarse pero que lo ven muy difícil. Dos de los pocos agricultores que quedan en un municipio de fuerte tradición hortícola son hermanos jóvenes. Subsisten gracias a que entre los dos realizan toda la cadena de producción, distribución, y venta, por lo que pueden ahorrar en intermediarios. En cambio, creen que con toda la legislación que se les viene encima «en dos o tres años tal vez tengamos que irnos a vivir a Segovia. ¿A qué? Pues no se, a lo que haya supongo». «Los productos hortícolas de aquí tenían fama en todo el país, pero ahora solo estamos 4 en ello». El joven agricultor afirma que técnicas como las ecológicas podrían ser interesantes porque podría subir el valor de los productos, pero para ello necesitaría el apoyo de técnicos en la materia.

Los jóvenes de la zona crecen muchas veces pensando que van a emigrar. Su entorno se lo refuerza continuamente, y por lo común los padres no animan a sus hijos a que se queden, sino todo lo contrario. Un panadero con oficio «de toda la vida» nos cuenta que «a mi hijo de 18 le animo a que se vaya, este es un trabajo muy sacrificado, aquí no se quiere quedar nadie. Los inmigrantes vienen a la construcción, a los cerdos, y poco más. Están construyendo 10 chalets a las afueras, tenían planeado 40, pero solo han vendido uno». Los padres por lo general transmiten a sus hijos una falta de fe en el lugar, aunque paradójicamente el ideal de la mayoría es que los jóvenes no se vayan.

- Inmigración. La Campiña está rápidamente cambiando. Mientras el éxodo juvenil continúa, la inmigración se ha acelerado. Ante la aparente contradicción de que subsistan al mismo tiempo emigración e inmigración, los entrevistados suelen referirse a dos razones: el carácter sacrificado de las labores de campo, a las cuales están más dispuestos las personas con mayores necesidades como los inmigrantes, y la escasez de atractivos para los jóvenes. Así, vemos sentimientos encontrados. Por un lado creen que el inmigrante es necesario por la falta de mano de obra. Por otro lado, prefieren que el crecimiento demográfico sea endógeno, manteniendo la identidad y valores propios, y que los jóvenes se queden. Pero finalmente animan a sus hijos a que se vayan a la ciudad. El análisis y resolución de estos sentimientos cruzados puede ser una clave para la búsqueda de soluciones a las necesidades y problemas de este medio rural.

- El abandono de los productos propios de elaboración tradicional. La falta de confianza en el futuro de su lugar y el progresivo abandono de sus productos choca con la riqueza con la que dan cuenta los entrevistados sobre las características 
diferenciales de su producción. Las personas que elaboran productos tradicionales suelen explicar con mucha sencillez, claridad, y detalle las cualidades de su elaboración artesanal. El producto se hace con más cuidado, más lentamente, por lo que conserva mejor sus propiedades naturales, con componentes y técnicas adaptadas al lugar, por lo que supone valores culturales y ecológicos a la vez que un conocimiento acumulado sobre la manera más adecuada de preservar sus cualidades. Un ejemplo es el molinero del Molino de Carrascal, en el municipio de Las Huertas, abierto en 1631 y en funcionamiento ininterrumpido desde entonces, que pueden cerrar en breve al jubilarse. Para él, el molino es «dónde nace la harina antigua». El proceso de producción de esta harina «es más lento, calienta menos la harina». Al ser de piedra, no alberga partículas o sabores metálicos de los molinos actuales industriales. Con la piedra, la harina «mantiene más las propiedades, el aroma, y el sabor». A la pregunta de si le interesaría recibir encargos de alguna empresa de panadería de calidad, contesta que no le interesa el negocio, aunque «todo dependería de cuánto pagasen, claro».

Integrando necesidades, proyectos, e ideales. En general, los datos demográficos y económicos recientes se complementan con las percepciones de necesidades, soluciones, e ideales, y nos explican en buena parte el paso rápido de una comarca con una distribución más o menos homogénea, con cierta conectividad y redes sociales y productivas, y una relación estrecha y apegada al lugar, a una situación de progresivo desequilibrio entre municipios, con éxodo humano autóctono y una menor asociación con el territorio como generador de calidad de vida y desarrollo, mientras que se concentran las actividades productivas y la nueva población en modelos económicos más especializados y desligados de las características del territorio. Todo ello nos muestra un riesgo de fracturación territorial importante, por un lado con fuerzas que fragmentan social y económicamente la estructura territorial y la relación con el territorio y por otro lado con fuerzas centrífugas que hacen tirar la comarca hacia el norte y hacia el sur. Todo ello viene corroborado por una desvalorización y abandono de diversos recursos culturales y naturales propios del territorio y en particular del conocimiento local como capital social.

Si a eso unimos las paradojas y deseos cruzados señalados, los habitantes perciben un futuro desolador, observando que algunos municipios pueden desaparecer en cuestión de 1 o 2 generaciones mientras que otros municipios parece en principio que se puedan mantener con la inmigración extranjera o con la entrada de residentes de ciudad, bien como primera vivienda bien como segunda vivienda. En parte esta visión fatalista y hasta derrotista que comparte una mayoría resignada de la población de la Campiña podría llegar a hacerse real en un claro caso de «profecía autocumplida», amenazando el modo de vida como los recursos del propio territorio.

\subsection{Recursos de la Comarca}

Ante las necesidades y problemas sociales aquí delineados, se procedió a identificar y analizar una serie de recursos a nivel municipal y comarcal, que se sintetiza a continuación:

Agricultura y productos derivados. La agricultura es quizá el primer valor a resaltar que caracteriza la tradición, identidad, y calidad de los productos de la Campiña Segoviana. En particular la agricultura de secano se adapta bien a las circunstancias ambientales y del terreno. Los habitantes de la Campiña utilizar técnicas ancestrales de cultivo en secano que implican un gran ahorro de agua, lo que supone un valor económico y ambiental añadido. Al mismo tiempo, los productos de secano muestran más propiedades nutritivas y cuali- 
dades culinarias que los de regadío. Los productos derivados del secano, sobre todo los provenientes del molido de cereales y harinas, en particular del trigo, como son sus panes, bollos, galletas, bizcochos, etc., u otros como los aceites de girasol, albergan características de calidad ecológica y cualidades tradicionales y artesanales, de valiosos conocimientos populares y tradicionales sobre el lugar, que reflejan la identidad cultural de la Comarca. Los productos de huerta de la comarca también tienen un espacio con grandes potenciales, y muchos han gozado en el pasado de amplio prestigio en toda la región, como son las alubias, los pimientos, las patatas, o el calabacín, y sus productos culinarios derivados.

Los productos de recolección, en particular de los pinares (piñones y resinas), también son recursos agrícolas que no se deben desdeñar, por sus valores de confluencia entre alimentación de calidad, ecología, cultura, y turismo. Posibilidades de un agroturismo de recolección pueden suponer un ejemplo de integración sinérgica entre actividades. Existe todavía alguna festividad de recolección de piñones que puede ser un ejemplo de difusión turística al mismo tiempo que de dinamización social. La zona también tiene una gran tradición de resina de pino. Desafortunadamente, los precios a nivel internacional hacen muy difícil poder competir. Es necesario resaltar valores añadidos a este recurso tan presente y con tantos potenciales.

Productos ganaderos y derivados. Es innegable el gran potencial de los productos derivados, sobre todo de las especies porcina y ovina. Los conocimientos tradicionales del lugar están íntimamente intrincados en todo el proceso desde la crianza de los animales hasta el productos finales como muchos tipos de embutidos de cerdo o los quesos y yogures de oveja, de enorme riqueza diferencial y singularidad, que aúnan integración ecológica y territorial con historia cultural, y que representan cadenas de valor con grandes potencialidades.

Vinos. La comarca muestra una gran tradición vinícola, y quizás debería buscarse una identidad y etiquetado distinguible sin por ello perder su inclusión en las importantes denominaciones de origen de Rivera de Duero y Rueda. Entre sus valores se encuentra la integración entre conocimientos tradicionales y adaptación ecológica. Según una productora de Nieva, la zona es la mejor del mundo para la variedad Berdejo, por el clima y la composición de la tierra, que facilita una maduración lenta y homogénea de la uva. La producción de esta variedad de vino se lleva realizando desde la Edad Media. Las cepas que todavía quedan con «pie franco» (con raíz propia de la variedad) son un compendio de virtudes. Una planta $100 \%$ berdejo está completamente adaptada al lugar, y por ello la uva madura de forma muy apropiada y refleja todas las cualidades diferenciales de la tierra y el suelo. Se adapta también mejor a las contingencias climáticas del lugar, por lo que no necesita riego, superando mejor las sequías. En cambio, la forma en red de las raíces tiene un alto riesgo de contagio de enfermedades como la Phylloxera, por lo que solo quedan las antiguas, antes de ser prohibidas. La conjunción entre cultura, historia, adaptación al lugar, y calidad ecológica merece un estudio biológico para su recuperación.

Recursos naturales. Al igual que la resina en otros tiempos, todavía existen otros recursos naturales de gran calidad que generan buena parte del empleo directo e indirecto de varios municipios. Ejemplos de ellos son las canteras para pizarras, cuarzos o para material de construcción. Cuidando el punto ecológico pueden representar un recursos sostenible siempre que se le de el valor adecuado. También es fundamental señalar la gran riqueza del paisaje natural como recurso turístico, del que se está haciendo ya un importante esfuerzo de valorización y divulgación.

Industria. La industria está presente en la comarca de la Campiña y en muchos casos se cruza con otros procesos, como son los de fabricación de productos derivados de la ga- 
nadería, o los de explotación de recursos naturales. Así, es importante plantear la industria alineándola con otros sectores estratégicos de la comarca.

Patrimonio cultural / Turismo, rutas turísticas. La comarca alberga multitud de ejemplos del patrimonio arqueológico, arquitectónico, histórico-cultural, artístico, y no tangible y vivo como son sus tradiciones, artes, artesanías, fiestas, danzas (como el paloteo, que conjuga cultura, historia, música, y arte marcial), que suponen una riquísima red de conocimientos locales. Tratado de forma estratégica puede ayudar a re-articular el territorio, aprovechando oportunidades como la promoción de rutas que tradicionalmente lo han vertebrado en el pasado, que son la Ruta Jacobea, y la ruta verde surgida del antiguo ferrocarril, con sus potenciales centros culturales y turísticos en las maravillosa estaciones hoy abandonadas. Pero no debemos de convertir el turismo como única panacea y debe de alinearse con el resto de las intervenciones y recursos, como son los procesos y productos agropecuarios o la educación «in situ» sobre las costumbres del lugar. Un turismo cultural y ambientalmente activo va a suponer un consumo más diversificado, y la consiguiente distribución de riqueza y apoyo a su diversidad de recursos. Las casas tradicionales de valor histórico-artístico son uno de los grandes patrimonios de la Campiña, y grandes recursos de desarrollo, principalmente turístico. Frenar su abandono y potenciar su rehabilitación como casas rurales puede representar una mayor inversión a medio y largo plazo que la opción de la construcción de segundas viviendas, las cuales nunca dejarán tanto ingreso en la zona, pero sí un impacto irreversible al patrimonio urbanístico, cultural, y ambiental.

Recursos informales. Se hace evidente que las carencias en recursos sociales formales se suplen a través de sistemas tradicionales y populares de apoyo y organización social que incluye todo tipo de conocimientos y costumbres sociales y acaban formando un rico tejido multidimensional de conexiones sociales que facilita la subsistencia de la población. Estas redes territoriales de recursos informales son el auténtico colchón que ha conseguido llegar a nuestros días y que pueden servir de catapulta para un desarrollo territorial sostenible ambiental, social, cultural, y económico, aunque son justo estas redes las que pueden estar siendo más amenazadas por una eminente fractura y concentración demográfica.

El mayor recurso, la Comarca de la Campiña. Vemos cómo todos estos recursos están íntimamente ligados al territorio y en buena parte son recursos por ellos mismo. Es fundamental que todos ellos se entrelacen en su desarrollo, buscando la integración territorial de esta diversidad, aprovechando óptimamente la distribución de esta riqueza. Todo ello con el objetivo de hacer del territorio comarcal un recurso en sí mismo desde la dinamización de la creatividad colectiva a partir de sus valores.

Analizando todos estos recursos a la luz de las necesidades arriba identificadas, podemos observar que existen unas características que se encuentran en todos ello que son los conocimientos locales, recursos trasversales que identifican a la Campiña y que en esta comarca son de gran riqueza y variedad, auque se están perdiendo rápidamente. No solo son recursos los conocimientos tradicionales y populares sobre procesos productivos, sino también aquellos relacionados con los sistemas de apoyo y convivencia social, las artes, la cultural, el ocio, que suponen materias primas para la creatividad y por ello para la innovación emprendedora. De esta red de conocimientos, auténtico patrimonio cultural vivo, pueden surgir ejes catalizadores y estratégicos del desarrollo de la comarca si desde estudios geográficos los cartografiamos y ordenamos territorialmente en sistemas de cadenas de valor como estructuras vertebradoras de la comarca, y como básico capital social que permita recuperar la cohesión social, la confianza y la ilusión por su futuro. 


\section{Análisis, implicaciones y conclusiones generales}

\subsection{Integrando necesidades y recursos}

El análisis final de los resultados integra de datos secundarios y primarios, y cuantitativos y cualitativos de nuestro estudio y de la convergencia entre las necesidades objetivas y percibidas y los proyectos, ideales, potenciales y recursos sociales, económicos, y etnológicos identificados y analizados.

De los ideales a las realidades. Empezando por el final, que son los ideales sobre el lugar, contrastándolos con la situación actual, cabe decir que existe una gran convergencia entre esta realidad y los temores que albergan estos deseos, tan llenos de ansiedad. Un deseo general que es ver el lugar crecer de forma natural y sobre su propia identidad, aparece aquí casi como utopía. Los jóvenes marchan en buena parte debido a 3 razones principales: (1) El sacrificio que implica el trabajo del campo y su contraste con lo que ellos perciben que es el trabajo en la ciudad, (2) la propia desvaloración de sus lugares, que no parecen relacionar con lo que entienden por calidad de vida, en contraposición a los valores de la ciudad, y (3) la falta de servicios de ocio, culturales, o de consumo en los pueblos. Todo ello hace que lo jóvenes asocien fracaso con la permanencia en el lugar. Esto aparece como ineludible. Los jóvenes parecen irse irremediablemente y sus padres en el mejor de los casos no hacen nada para convencerles a quedarse. Este fenómeno, generalizado en el mundo rural («el vacío rural», García y García, 2004) puede ir unido a la tendencia encontrada de disociar sus concepciones de calidad de vida con su entorno territorial.

De los recursos a las soluciones. Ante cierta desolación que surge de las necesidades analizadas, aparecen al mismo tiempo grandes oportunidades desde recursos, potenciales, y propuestas en relación a esas necesidades, que con el debido apoyo pueden tener una más que interesante salida. Se hace necesario alinear sinérgicamente los valores de los productos en cadenas bien diferenciables. Se trata de promover una diversidad de cualidades culturales, ecológicas, de calidad, y de salud, integradas en muchos procesos y productos de la Campiña Segoviana. Y como hemos visto, es el conocimiento local, tradicional y popular sobre el territorio la característica en común de todos estos valores. Un desarrollo basado en el estudio y gestión de la relación entre conocimiento local y territorio puede hacer confluir todos los valores.

Al mismo tiempo y para todo ello, se hace básico que en el ámbito operativo las administraciones públicas potencien el apoyo técnico para profundizar en el estudio geográfico y promoción de la diversidad de recursos del territorio comarcal, para identificar e impulsar colectivamente líneas de desarrollo económico que permitan una mayor vertebración y cohesión territorial y a la vez que busquen sinergias entre sectores económicos. Es necesaria también la atención técnica para facilitar la adecuación de las nuevas oportunidades del agricultor o el ganadero a los crecientes requisitos legales y administrativos de la Unión Europea y de las administraciones regionales y nacionales, o para poder poner en marcha y obtener ayudas y subvenciones a los nuevos proyectos emprendedores o nuevas oportunidades como los cultivos ecológicos. O, desde enfoques estratégicos, para estudiar la distribución de las fuerzas laborales en cada sector, analizando cargas laborales y funciones, buscando fórmulas de redistribución y complementación a nivel comarcal.

Además, una gestión centrada en la relación directa con el consumidor final facilitaría superar dificultades de distribución y comercialización. El producto debe de llegar al consumidor claramente identificado y diferenciado, dotado de la información y conocimiento 
suficiente junto al producto, con una orientación didáctica. La promoción del turismo entre los mismos consumidores puede convertir a estos en excelentes agentes de control de la calidad del proceso de una «trazabilidad participativa» y de una cogestión de la distribución de los productos, facilitando el concepto de cadena de valor centrada en la relación con la demanda. Todo ello puede hacer además que un producto de calidad tenga un proceso más bajo en costes y por ello más competitivo. Para ello las nuevas tecnologías de comunicación permiten una relación más personalizada, simplificada y fácil con una demanda más diversa. Es fundamental para ello que las diferentes administraciones faciliten y apoyen estos proyectos y productos una vez probada su viabilidad.

En cuanto al recurso humano, la mayor queja se refiere a los sacrificados horarios y la falta de vacaciones («como en la ciudad»). La solución parte de un análisis para la re-distribución de cargas laborales desde un enfoque colectivo y territorial, con un fortalecimiento de la colaboración entre sectores productivos. Esto no es fácil en la estructura social actual de la Comarca, que se ha ido disgregando en las últimas décadas. Se debe de aunar los esfuerzos verticalmente y horizontalmente (en forma de cooperativas o de simples redes) para facilitar diferentes tipos de jornadas laborales más llevaderas, teniendo, bien organizada, una mayor flexibilidad laboral para todos. En este sentido, habría que estimular la implicación del trabajador a nivel vertical, y la participación en más de un negocio o actividad dentro de cada cadena productiva, como así era tradicionalmente. Esto multiplicaría el recurso humano en las diferentes actividades, y la distribución de las cargas laborales, diversificando los ingresos, que serviría como amortiguador para cualquier crisis sectorial. Fortalecería la estructura vertical productiva desde la necesaria cooperación entre las partes, e impulsaría la cohesión social, promoviendo el conocimiento local y colectivo como capital social.

La diversificación de actividades es especialmente viable dentro de una misma cadena de valor. Por ejemplo, el mismo grupo que fabrica harina integral tradicional y ecológica, podría participar en la producción artesanal de pan y bollería y en su distribución y venta. Diversificación y trabajo colectivo, con la comarca como unidad territorial de gestión del trabajo, puede también contribuir a una mayor integración social del territorio, reordenándolo de forma más distributiva y evitando futuras fracturas y segmentaciones territoriales que no harían más que debilitar los potenciales de los recursos propios de la comarca. La estructuración territorial de las redes de valor en sistemas de cadenas optimizará los potenciales y recursos de todo el territorio. La identificación de nodos (actividades que pueden funcionar de intersecciones sinérgicas) entre cadenas de valor pueden ser los puntos de apoyo de esta estructura. Por ejemplo, molinos tradicionales como el de Carrascal son emblema y símbolo del proceso integral de los cereales de la Campiña. Aúnan tradición, historia, cultura, conocimiento popular, preservación ecológica (en este caso del río) y calidad, y al mismo tiempo puede ser usado en un turismo educativo que enseñe el proceso natural y tradicional de los productos de la comarca, no solo para escuelas sino para cualquier turista y potencial consumidor de los productos de la comarca. Un concepto territorial similar se puede aplicar a los servicios sociales, constituyendo sistemas de gestión en redes a nivel comarcal (aunando recursos municipales) y que puede ayudar a cubrir las grandes necesidades sociosanitarias de los mayores y sociolaborales de los jóvenes y mujeres y de ocio en general ya vistos.

Orgullo rural. El nivel más complicado, y por ello dejado para el final, es el ámbito socioafectivo. Nuestra sociedad moderna nos muestra machaconamente que el culmen del desarrollo, progreso y éxito está en la ciudad, que además se presenta con gran magnetismo para los jóvenes, por sus posibilidades de elección y vida social. Lo urbano se nos define como contrapuesto a lo rural, que es «retrasado», obsoleto (Lois y Santos, 2004), 
«paleto», ya que es asociado inevitablemente al lugar y al territorio (Escobar, 2000), a lo natural y primitivo como contrapuesto a lo «culto», y «civilizado» de la ciudad (Turner, 1994). Se hace necesario trabajar a todos los niveles contra la discriminación y desprecio hacia lo rural. Esta última es la tarea más difícil, porque justamente va en contra de ciertos concepciones desarrollistas muy extendidas aún en nuestra sociedad actual (Escobar 2000; Esteva, 2000).

\subsection{Conclusiones}

Podemos concluir finalmente que los resultados de este estudio mantienen las hipótesis formuladas en la introducción en relación a las necesidades y los recursos. Las principales necesidades de la comarca pueden sintetizarse en las siguientes:

- Las mayores necesidades en la Campiña Segoviana están relacionadas con las carencias sociales que explican un continuo éxodo juvenil, no son únicamente económicas y de ordenación sociolaboral, sino también psicosociales (magnetismo de la ciudad que se relaciona con el progreso individual y familiar, disociación de conceptos de calidad de vida con el entorno social y ambiental, desvalorización del medio rural, individualización de la vida cotidiana y de las concepciones de calidad de vida, que no favorecen el apego, el interés, y la confianza y valor por el lugar y el territorio).

- Las necesidades y problemas siguientes son consecuencia en parte de las primeras. Por un lado tenemos el envejecimiento, y los trastornos sociales que conllevan, como la soledad o la disminución de recursos informales de apoyo y organización social, tanto para ámbitos de salud, bienestar y calidad de vida, como de proyectos emprendedores.

- Otro tipo de necesidades tienen que ver con las anteriores y con el deterioro de los propios recursos, especialmente del patrimonio no tangible, conocimientos y costumbres tradicionales, populares y colectivas, básicos como materia prima para la creatividad, la innovación y el desarrollo. Por otro lado, son escasos los centros sociales y de salud para los mayores y los de promoción laboral y culturales para los jóvenes. Finalmente, los modelos económicos emergidos espontáneamente (construcción, hostelería, nuevos cultivos de regadío...), están absorbiendo buena parte de la inmigración internacional y concentrándola en zonas ya de por si más pobladas, mientras que los municipios pequeños siguen despoblándose.

Todo ello parece poner en riesgo el equilibrio, la distribución de recursos, la conectividad territorial, y la integración social entre sí y con el territorio que caracterizan a la Campiña, y que son valores básicos para su futuro desarrollo. Dicho de otra forma, los resultados de este estudio, en sus diferentes niveles, confluyen en indicar una creciente fragmentación social del territorio y una fracturación social con el territorio. En cambio, nuestros resultados nos muestran también grandes posibilidades con los que la comarca aún cuenta y nos sugieren un panorama lleno de oportunidades. El equilibrio y conexión territorial de una gran diversidad de recursos propios puede ser el principal motor no solo para atajar las amenazas, sino para aprovechar las oportunidades de desarrollo, superando las principales problemáticas y satisfaciendo las principales necesidades sociales de la Campiña. Para ello, a continuación se sintetiza una serie de líneas estratégicas que surgen de todo este análisis. 


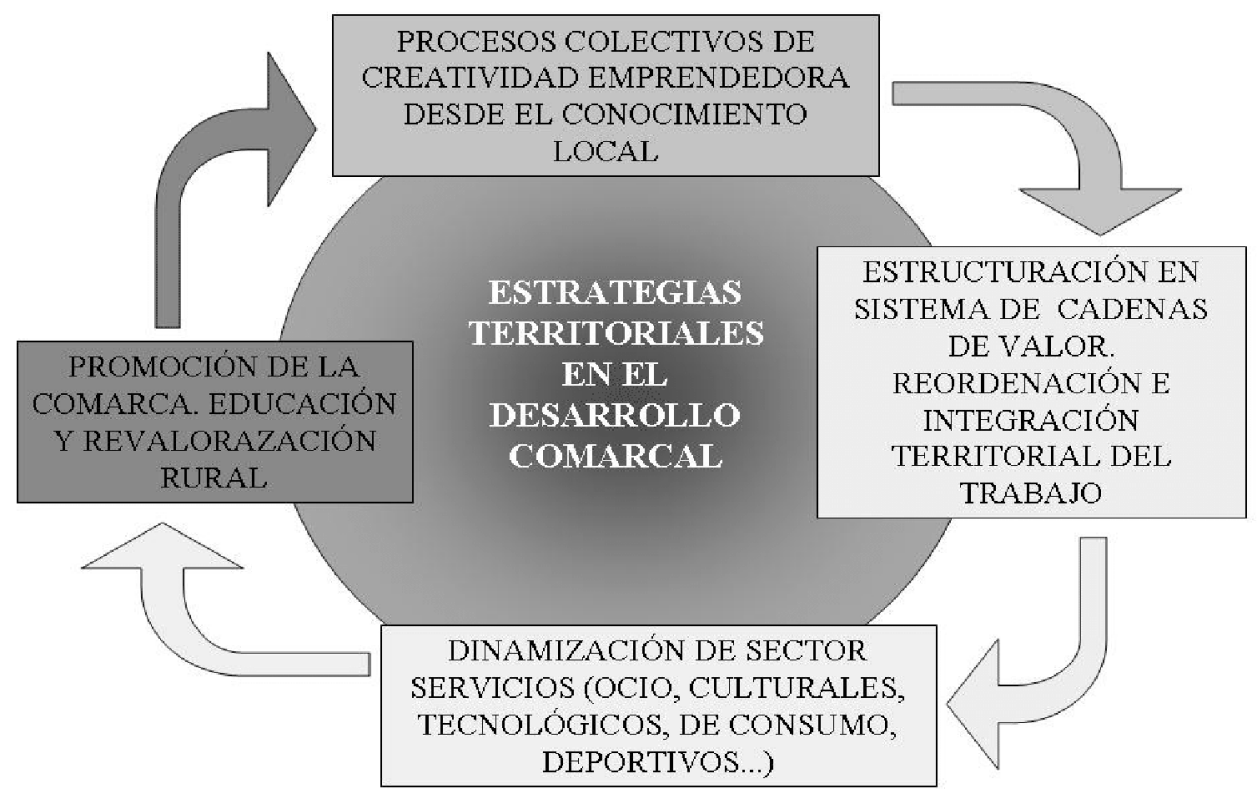

GRÁFICO 2. Representación gráfica de ejes estratégicos del desarrollo comarcal de la Campilla Segoviana y procesos de gestión entre ellos.

Líneas estratégicas. Sintetizando, se propone un modelo de desarrollo que, partiendo de las necesidades, los ideales y deseos, propuestas de soluciones y recursos identificados en este estudio, procuraría una dinámica cuyo objetivo básico es el de un desarrollo social, cultural, territorial, y demográficamente sostenible e integrado (ver Gráfico 2). En este modelo, cuatro serían lo pilares que servirían de dinamizadores mutuos basados en los principales grupos de necesidades y recursos identificados:

1. La puesta en valor económica y promoción de las actividades y productos propios y que puedan surgir del intercambio y desarrollo de los conocimientos propios del lugar. Para ello, son básicos los espacios multi-laborales de análisis de posibilidades y potencialidades para la identificación e impulso de cadenas de valor desde el propio conocimiento, posibilitando la creatividad colectiva, y la innovación en proyectos inter-emprendedores conjuntos, basándose en la confianza sobre el propio capital social y sobre su crecimiento, y con el papel de las empresas como motores de conocimiento local para el desarrollo sostenible desde su trabajo en el territorio.

2. La redistribución, diversificación, e integración territorial de los trabajos y cargas laborales, desde la constitución de grupos, empresas, colectivos, y cooperativas de trabajo conjunto a nivel comarcal, que incluya no solo conglomerados de sectores productivos, sino que procure integrar verticalmente ciclos productivos completos en cadenas de valor, identificando «nodos» sinérgicos entre ellas hacia una estructura territorial vertebradora de la comarca. Todo ello buscando diversificar de forma territorialmente distributiva los productos, integrar territorialmente el trabajo y el 
apoyo mutuo, y hacer el trabajo más cómodo y atractivo para los jóvenes. Estas líneas encajan bien con estrategias recomendadas por diferentes autores actuales sobre la re-territorialización rural (Borja y Castells, 1997; Entrena, 1999; Márquez, 2002; Pujadas y Font, 1998) o sobre los potenciales de la escala comarcal (Gómez, 2001; Guiberteau, 2002).

3. La creación de espacios de servicios sociales, sanitarios, culturales, y ocio, tanto desde las administraciones públicas como de las empresas privadas. Las líneas 1 y 2 pueden impulsar este sector y se abrirán oportunidades de negocio en servicios.

4. La promoción de la Campiña puede y debe hacerse no solo desde campañas de marketing externo sino también interno, centrándose en la educación de los valores y recursos de la comarca. Se puede sugerir la exploración de una o varias marcas de calidad que simbólicamente sean capaces de sintetizar, aglutinar y cristalizar los valores y recursos estratégicos e identitarios de la Campiña Segoviana y que facilite una promoción unitaria y sinérgica y que contribuyan a una mayor cohesión social hacia el desarrollo de la comarca. Finalmente, la educación y revalorización rural debe de ser una tarea desde lo «micro», las escuelas de la comarca, hasta lo «macro» (rural y urbano), en una necesaria sensibilización y cambio cultural de actitudes y concepciones sobre el mundo rural y su situación, entendiendo esta como un problema de todos.

\subsection{Implicaciones para el desarrollo rural. Los potenciales de la gestión del conocimiento local en cadenas de valor}

La Campiña Segoviana muestra similares necesidades y problemáticas no solo de la península ibérica, sino que en muchos sentidos, comparte los mismos dilemas del mundo rural a nivel internacional. Por eso, creemos que estas líneas estratégicas de dinamización y desarrollo local pudieran ser aplicables a otros territorios rurales no solo de España. En este sentido, la gestión, ordenación, y desarrollo de los conocimientos locales dentro de las cadenas de valor puede tener una serie de potenciales que pueden permitir su aplicación en diferentes territorios de diferentes países, entre ellas:

- La gestión y el desarrollo de la red de conocimientos surgidos en el territorio e interadaptados a él a través de generaciones, pero también dinámicos y en continuo cambio, nos va a permitir un desarrollo local y regional basado en el respeto, preservación y dinamización territorial, y en el enriquecimiento mutuo entre diversidad cultural y natural (la «gestión ecocultural», Gandarillas, 2000).

- Los conocimientos locales, valores vivos que surgen y pertenecen a la propia comunidad y al territorio, son recursos endógenos, respetuosos con la propia cultura, y con las propias concepciones y valores de desarrollo de la comunidad, lo que va a facilitar un desarrollo más implicado y eficaz (Recasens, 2000).

- La gestión, revalorización, y desarrollo de estos conocimientos, de la «tradición de la sabiduría» popular (Gaudiani, 1999), su puesta en común e intercambio colectivo confluyéndolo al mismo tiempo con el conocimiento formal, científico, «global» (Hess, 2006) permite la creatividad y la innovación hacia proyectos emprendedores colectivos.

- Todo ello potencia la confianza mutua, la cohesión social, la cooperación, el tejido social, y el desarrollo del capital social como activo principal de una comunidad (Mairal y Gandarillas, 2005), dinamizando cualidades psicosociales, como la autoestima, el valor y la creencia por el propio futuro colectivo y del lugar, el interés y ánimo 
para invertir esfuerzos en ello, para activar recursos propios hacia la potenciación colectiva en base a la revalorización y confianza sobre los propios conocimientos y posibilidades.

- El análisis de los conocimientos locales como redes de valor y su ordenación en cadenas facilitan alinear sinérgicamente la riqueza de valores, y de calidad de los productos, permitiéndonos desarrollar una economía más flexible, adaptable y centrada en la relación con la demanda (ver Allee, 2003, para una metodología de análisis de redes de valor).

- Fomentar la creatividad desde la puesta en común de los conocimientos locales como materia prima de las cadenas de valor permite una adaptación continua a la demanda. La cadena de valor de los conocimientos locales puede servir como vector de adaptación mutua entre la singularidad de un territorio y la personalización de la demanda.

- Las cadenas de conocimiento local facilitan el aprovechamiento de las nuevas tecnologías de comunicación, que facilitan a su vez hacer participe al cliente final en la cadena, colaborando en la creación de nuevo conocimiento, implicándolo activamente en la preservación y dinamización de los valores del territorio y en sus conocimientos y al mismo tiempo fortaleciendo así la fidelización del cliente y una oferta diversificada, accesible, y centrada en la relación con un cliente activo, agente de control y trazabilidad.

- Además, los propios conocimientos pueden ser inmejorables recursos de promoción, en si mismos diferenciadores, identificadores, y escaparates de los productos, ya que el conocimiento implica una muestra didáctica de los que se quiere ofrecer.

- Desde este enfoque, el diagnóstico geográfico nos puede permitir una cartografía de las redes de conocimiento local que diferencie entre puntos de concentración e integración de conocimientos (con alta diversidad y creatividad) y áreas de especialización.

- Todo ello nos permite diseñar una estructuración territorial desde redes de conocimientos locales «vectorializados» en cadenas de valor, identificando nodos entre cadenas articulándolos sinérgicamente con las redes de conectores ecológicos (definiendo redes y corredores «ecoculturales» de desarrollo sostenible), optimizando así la vertebración del territorio, preservando un equilibrio y distribución demográfica apropiada que sepa aprovechar adecuadamente los recursos del territorio.

- Con ello, conseguimos una gestión social y económica que parta del territorio y así maximizaremos la obtención de productos de mayor calidad ya que estarán más adaptados al territorio.

- Finalmente, la gestión y ordenación de estructuras territoriales desde las redes de conocimiento local, al favorecer la interacción, colaboración, y cohesión social, contribuirá también a fortalecer el tejido social y el apoyo social como recurso informal hacia diferentes necesidades sociales de colectivos como los mayores o los jóvenes. En particular, el conocimiento y la sabiduría popular de y sobre un lugar revaloriza el papel de la persona mayor como principal depositario y potencia la comunicación y transmisión intergeneracional y las redes de apoyo social.

Por supuesto que a la hora de poner en práctica estos principios, debemos de ser conscientes de que el conocimiento local por si mismo no es suficiente (Escobar, 2000; Frank y Smith, 1999) y de las limitaciones y riesgos que la dinamización colectiva de los conocimientos locales y las diferentes metodologías de diseño de cadenas de valor han mostrado en diversas experiencias (Chase, 1993; Douwe van der Ploeg, 2000; Millar, Haverkort, Van Hooft, Hiemstra, 2001; Recasens, 2000). En cambio, y aunque no sean la «varita mágica», de cara a afrontar los retos del mundo rural actual, la gestión del conocimiento local debería de considerarse una sólida línea estratégica de acción y desarrollo. 


\section{Referencias}

ALLEE, V. (2003). The Future of Knowledge: Increasing Prosperity through Value Networks. Burlington: Butterworth-Heinemann.

CHASE, A. (1993). «Traditional Ecological Knowledge. Wisdom for Sustainable Development». Australian Journal of Anthropology, 4(3), 245-247.

BORJA, J., y CASTELLS, M. (1997). Local y Global. La Gestión de las Ciudades en la Era de la Información. Madrid: Taurus.

DIAZ, L. (1984). Rito y tradición oral en Castilla y León. Valladolid: Ed. Ámbito.

DIAZ, L. (1998). Aproximación antropológica a Castilla y León. Barcelona: Anthropos.

DOUWE VAN DER PLOEG, J. (2000). «Sistemas de conocimiento, metáfora y campo de interacción: el caso del cultivo de la patata en el altiplano peruano». En Viola (comp.): Antropología del Desarrollo. Teorías y Estudios Etnográficos en America Latina, pp. 359-380. Barcelona: Paidos.

CHAMPETIER, Y. (2002). «Procesos innovadores en el medio rural. La innovación al servicio del desarrollo territorial». En D. Márquez (Coor.): Nuevos Horizontes en el Desarrollo Rural, pp. 157-174. Madrid: Akal.

ENTRENA, D. (1999). «La desterritorialización de las comunidades locales rurales y su creciente consideración como unidades de desarrollo». Revista de Desarrollo Rural y Cooperativismo Agrario, 3, pp. 29-41. Unidad de Economía Agraria de la Universidad de Zaragoza.

ESCOBAR, A. (2000). «El lugar de la naturaleza y la naturaleza del lugar: Globalización o posdesarrollo». En Viola (comp.): Antropología del Desarrollo. Teorías y Estudios Etnográficos en América Latina, pp. 169-216. Barcelona: Paidos.

ESTEVA, G. (2000). «Desarrollo». En Viola (comp.): Antropología del Desarrollo. Teorías y Estudios Etnográficos en America Latina, pp. 67-101. Barcelona: Paidos.

FRANK, F., y SMITH, A. (1999). The Community Development Handbook. A Tool to Build Community Capacity. Canadá: Labour Market Learning and Development, Gobierno de Canadá.

GANDARILLAS, M.A. (2000). «El espejo del Sur: La integración ecocultural como alternativa a los dilemas de Occidente». En Univ. SEK: Anuario de la Universidad SEK Internacional 2000, pp. 155-160.

GARCÍA, J.F., y GARCÍA, F.J. (2004). «Implicaciones socioeconómicas del desarrollo rural. Una visión a partir de Andalucía». En R. Rodríguez y E. Pérez (Coord.): Espacios y Desarrollos Rurales. Una Visión Múltiple desde Europa y América Latina, pp. 101-130. Gijón: Ediciones Trea.

GAUDIANI, C.L. (1999). «La sabiduría como capital en comunidades prósperas». En F. Hesselbein, M. Goldsmith, R. Beckhard, y R.F. Schubert (Comp.): La Comunidad del Futuro, pp. 85-97. Barcelona: Granica.

GÓMEZ, D. (2001). Ordenación Territorial. Madrid: Ed. Agrícola Española.

GUIBERTEAU,A. (2002). Fortalezas y debilidades del modelo de desarrollo rural por los actores sociales. En D. Márquez (Coor.): Nuevos Horizontes en el Desarrollo Rural, pp. 87-104. Madrid: Akal.

HAMMERSLEY, M. y ATKINSON, P. (1994) Etnografía. Métodos de investigación. Barcelona: Paidos.

HESS, C.G. (2006). «Kowledge Managemente and Knowledge Systems for Rural Development». En: Reader: GTZ Knowledge Managemente. GTZ Sector Project Knowledge Systems in Rural Development, www.gtz.de/agriservice, extraido 20/10/2007.

HESTER, R.T. (2006). Design for Ecological Democracy. Inglaterra: MIT.

LESTA. E. (2001). «Participación y Desarrollo. La aportación de la psicología comunitaria». En M. Marchioni (Coord.): Comunidad y Cambio Social, pp. 129-148. España: Popular.

LOIS, R.C., y SANTOS, X.M. (2004). «Planificación y espontaneidad en el desarrollo rural». En R. Rodríguez y E. Pérez (Coord.): Espacios y Desarrollos Rurales. Una Visión Múltiple desde Europa y América Latina, pp. 131-156. Gijón: Trea.

MAIRAL, P., y GANDARILLAS, M. (2005). «Más allá de la sustentabilidad. Una propuesta ecocultural». En F.J. Garrido (Coord.): Desarrollo Sostenible y Agenda 21 Local. Prácticas, Metodología, y Teoría, pp. 79-86. Madrid: Iepala Editorial / Cimas

MAUSS, M. (1990). «Introducción a la Etnografía». Madrid: Ed. Istmo.

MÁRQUEZ, D. (2002). «Bases metodológicas para el desarrollo rural». En D. Márquez (Coor.): Nuevos Horizontes en el Desarrollo Rural, pp. 11-27. Madrid: Akal. 
MAYA, A. (2004). «La Unión Europea como promotora del desarrollo rural». En R. Rodríguez y E. Pérez (Coord.): Espacios y Desarrollos Rurales. Una Visión Múltiple desde Europa y América Latina, pp. 23-48. Gijón: Ediciones Trea.

MEDINA, J.E. (1996). «Los aspectos psicosociales y culturales en la competitividad y la gestión del desarrollo regional». En J. Medina y E. Variela (Comp.): Globalización y Gestión del Desarrollo Regional. Perspectivas Latinoamericanas, pp. 215-236. Colombia: Universidad del Valle.

MILLAR, D., HAVERKORT, B., VAN HOOFT, K., HIEMSTRA, W. (2001). «Challenging Developments. Approaches, results and perspectives for endogenous development». Compas Magazine, Marzo 2001, pp. 4-7.

MONTERO, M. (1998). «La comunidad como objeto y sujeto de la acción social». En A.M. González (Ed.): Psicología Comunitaria: Fundamentos y Aplicaciones. España: Síntesis.

MONTERO, M. (2004). «Introducción a la Psicología Comunitaria. Desarrollo, Conceptos, y Procesos». Buenos Aires: Paidos.

PUJADAS, R., y FONT, J. (1998). Ordenación y Planificación Territorial. Madrid: Síntesis.

RED DE ESPACIOS NATURALES PROTEGIDOS DE ANDALUCÍA (RENPA) (2002). Integración Territorial de de Espacios Naturales Protegidos y Conectividad Ecológica en Paisajes Mediterráneos. Consejería de Medio Ambiente, Junta de Andalucía.

RECASENS, A.V. (2000). La crisis del desarrollismo y el surgimiento de la antropología del desarrollo. En Viola (comp.): Antropología del Desarrollo. Teorías y Estudios Etnográficos en América Latina, pp. 9-64. Barcelona: Paidos.

SOLO, V. B. (2000). Reforma agraria, Revolución Verde y crisis de la sociedad rural en el México contemporáneo. En Viola (comp.): Antropología del Desarrollo. Teorías y Estudios Etnográficos en América Latina, pp. 305-359. Barcelona: Paidos.

SOMOZA, J. (2004). Implicaciones territoriales del desarrollo rural. En R. Rodríguez y E. Pérez (Coord.): Espacios y Desarrollos Rurales. Una Visión Múltiple desde Europa y América Latina, pp. 67-80. Gijón: Ediciones Trea.

TROITIÑO, M.A. (2000): El diagnóstico y la valoración del territorio. En J.L. García, D. Godeneau, y M.F. Febles (Editores): Instrumentos para el Desarrollo Local, pp. 51-77. Tenerife: Ayto de Santa Cruz de Tenerife.

TURNER, F. (1994). The Western Spirit Agaist the Wilderness. New York: Viking Press. 